\title{
A RARE CASE OF TRUE VAGINAL PROLAPSE IN A BITCH AFTER ABORTION DUE TO HYPOLUTEOIDISM
}

\section{A. ANTONOV \& M. KARADAEV}

Department of Obstetrics, Reproduction and Reproductive Disorders, Faculty of Veterinary Medicine, Trakia University, Stara Zagora, Bulgaria

\section{Summary}

Antonov, A. \& M. Karadaev, 2019. A rare case of true vaginal prolapse in a bitch after abortion due to hypoluteoidism. Bulg. J. Vet. Med., 22, No 4, 501-505.

The aim of the present report was to describe a clinical case of spontaneous true vaginal prolapse in a bitch as a complication of complete abortion due to hypoluteoidism 49 days after mating. Ovariohysterectomy and cervicopexy were performed after repositioning of the protruded vaginal wall. Both ovaries contained very small luteal bodies. In conclusion, the true vaginal prolapse without signs of dystocia in the present case could result from pelvic tissue relaxation following the abnormal luteal function and serum progesterone decline.

Key words: abortion, bitch, hypoluteoidism, pregnancy, vaginal prolapse

The most common causes of vaginal or vestibular masses in the bitch are vaginal prolapse and vaginal or urethral neoplasia protruding into the vaginal vault (Manothaiudom \& Johnston, 1991). In the bitch, there are two conditions, characterised with protrusion of vaginal tissue into and through the vulvar opening. Vaginal fold prolapse or hyperplasia occurs due to oedematous swelling of the vaginal mucosa during proestrus and estrus under the influence of estrogens (Johnston et al., 2001). The true vaginal prolapse is the other condition that reported near parturition under the influence of serum progesterone decline and in- creased estrogens. It is a very rare condition in the bitch and is occasionally observed in animals with constipation, dystocia or forced separation during breeding (Purswell, 2000; Alan et al., 2007, Ober et al., 2016).

Progesterone concentrations in serum or plasma are similar in pregnant and nonpregnant diestrous bitches, ranging from 10 to $70 \mathrm{ng} / \mathrm{mL}$ with peak values in early to mid-diestrus and a gradual decline to basal levels below 1 to $2 \mathrm{ng} / \mathrm{mL} 51$ to 82 days after the LH peak in nonpregnant bitches or 24 to 48 hours before parturition (Johnston et al., 2001). 
Hypoluteoidism is characterised by insufficient secretion of progesterone by the corpora lutea during pregnancy, which could lead to foetal resorption, abortion or premature delivery (Johnston et al., 2001; Görlinger et al., 2005). It is difficult to diagnose hypoluteoidism, because a decrease in plasma progesterone concentration is a normal physiological response to foetal distress and it accompanies premature delivery or abortion due to any cause (Johnston et al., 2001).

This is the first literature report on such a case of true vaginal prolapse in a bitch after abortion due to a premature decrease in serum progesterone concentration and without signs of dystocia.

\section{Case description}

A 5-year-old, nulliparous Cane Corso bitch, weighing $43 \mathrm{~kg}$, was presented to the Small Animal Clinic of the Faculty of Veterinary Medicine, Trakia University in Stara Zagora. The owner informed that the animal was mated 49 days ago and it was ultrasonographically diagnosed as pregnant 28 days after mating. The bitch was presented to the clinic because of abortion of 7 premature puppies, haemorrhagic vaginal discharge and a true vaginal prolapse (Fig. 1). The bitch had no history of vaginal fold prolapse during previous proestrus and estrus periods. According to the owner, there were no signs of dystocia and the prolapse occurred 20 minutes after the last puppy was delivered.

On physical examination, there were no changes in the general condition of the animal: rectal body temperature $37.8{ }^{\circ} \mathrm{C}$, heart rate $57 \mathrm{~min}^{-1}$, respiratory rate $27 \mathrm{~min}^{-1}$. The colour of visible mucosae was rose-red.

The inspection of the prolapsed vagina showed that the everted tissue was reddish, oedematous, without necrosis on

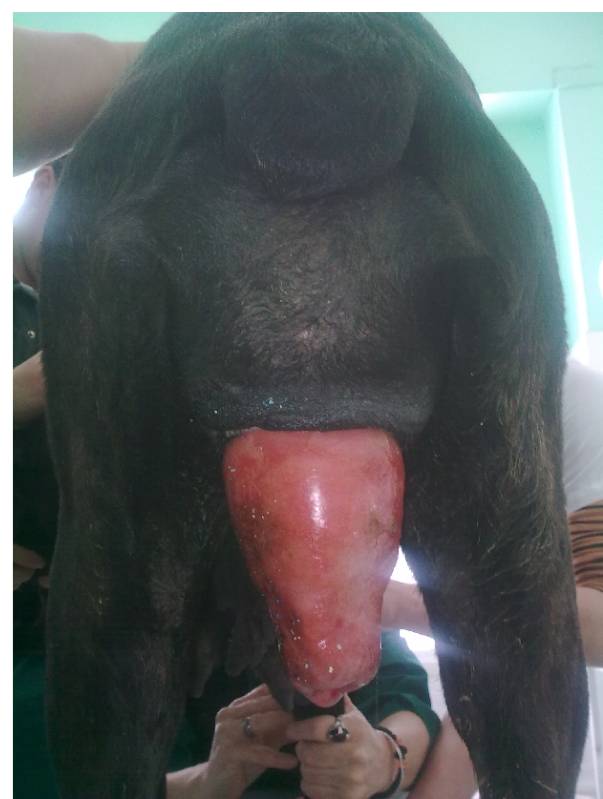

Fig. 1. Prolapsed vaginal tissue of the patient.

the surface and the cervix was viable. The mammary gland was slightly oedematous without lactation. Transabdominal ultrasonography (Mindray DC-6 Vet, China, $6.5 \mathrm{MHz}$ convex transducer) revealed no foetuses in the uterine horns. The urinary bladder was detected in its normal anatomic location.

To assay the levels of progesterone (P4), complete blood cell counts and biochemical parameters, blood samples ( $\sim 2 \mathrm{~mL})$ were collected by venipuncture of the cephalic vein. Complete blood cell counts were assayed on an automated haematological analyser BC-2800 Vet (Mindray, China), and blood biochemical parameters - on an automated biochemical analyser BS 120 (Mindray, China). Serum progesterone levels were measured by an enzyme immunoassay (EIA) using progesterone kit (Human, PROG ELISA, GmBh, Germany). Blood laboratory analysis showed no changes in the parameters 
and a serum progesterone concentration of $0.96 \mathrm{ng} / \mathrm{mL}$, so the patient was diagnosed with hypoluteoidism. The bitch was serologically tested for canine herpesvirus and Brucella canis and the results were negative.

It was impossible to replace the prolapsed vaginal tissue only by digital manipulation, so a decision for laparotomy was made. After aseptic preparation of the abdominal, vulvar and anal regions, the bitch was premedicated subcutaneously with $0.04 \mathrm{mg} / \mathrm{kg}$ atropine sulfate (Atropinum sulfuricum; Sopharma; Bulgaria). Fifteen minutes later, anaesthesia was induced by intravenous administration of $0.4 \mathrm{mg} / \mathrm{kg}$ diazepam (Diazepam; Sopharma; Bulgaria) and $10 \mathrm{mg} / \mathrm{kg}$ ketamine (Anaket 10\%; Richter Pharma Ag; Austria). After endotracheal intubation, the anaesthesia was maintained with isoflurane (TerrellTM; Minrad Inc.; USA). The bitch was placed in a dorsal recumbency and a median laparotomy was performed. Herniation of the uterine body was observed within the prolapsed vagina through the enlarged cervix (Fig. 2). The vagina and uterus were carefully reposi- tioned to their normal anatomic position by intraabdominal traction of the uterus and external digital manipulation of prolapsed vaginal tissue. An ovariohysterectomy was performed (Fig. 3). In order to prevent re-occurrence of the prolapse, a cervicopexy with USP $2 / 0$ polyglycolic acid absorbable sutures (Marlin; Catgut $\mathrm{GmbH}$; Markneukirchen) to the lateral abdominal wall was made. The abdominal cavity was closed with cross stitch pattern using USP 1 polyglycolic acid absorbable sutures (Marlin; Catgut GmbH; Markneukirchen), and the skin was sutured with simple interrupted non-absorbable sutures USP 1 (Vitalon; Dr Hammer \& Co. $\mathrm{GmbH}$; Hamburg). Post operative inspection of ovaries showed that both contained very small luteal bodies. Post operative treatment included oral application of antibiotic - $25 \mathrm{mg} / \mathrm{kg}$ amoxicillin-clavulanic acid (Synulox RTU; Zoetis; USA), for 5 days. Skin sutures were removed after 10 days. Follow-up examination showed that the patient was in a good condition; without re-occurrence of vaginal prolapse.

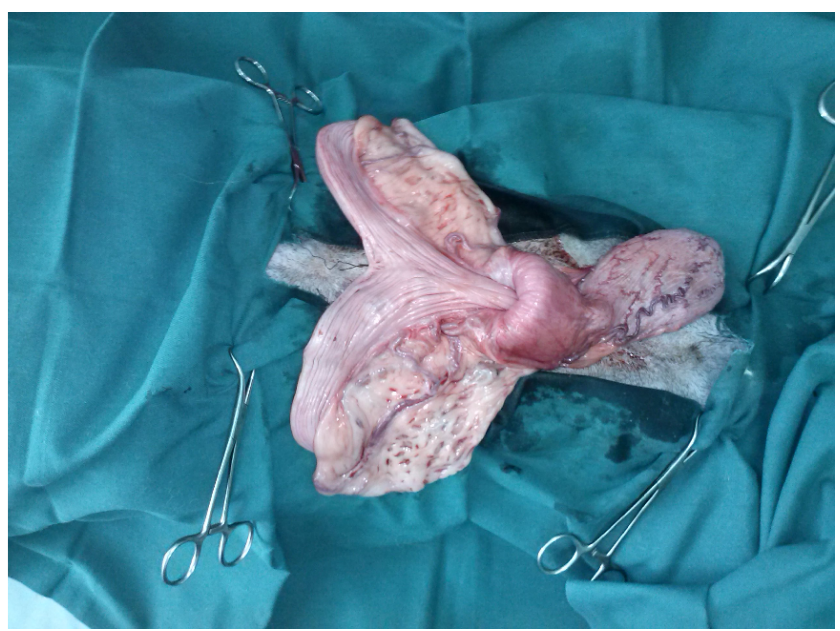

Fig. 2. Intraoperative appearance of the uterus of the patient after vaginal reposition. 


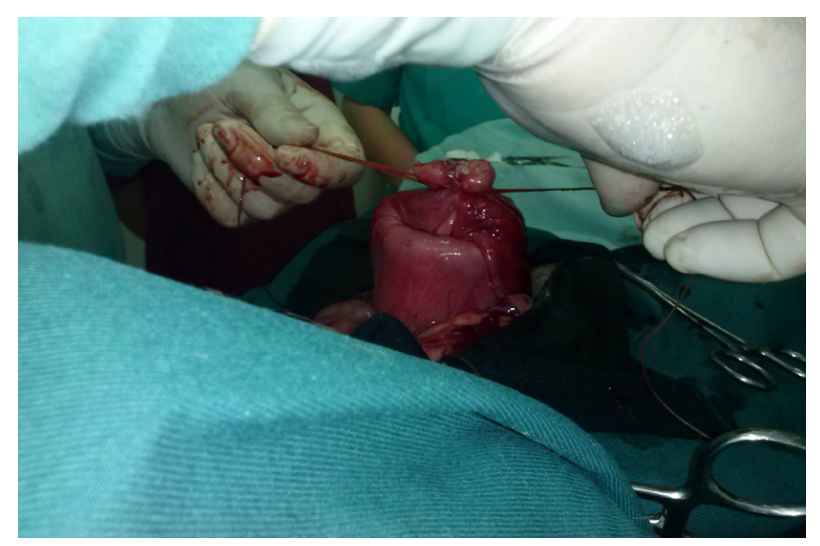

Fig. 3. Intraoperative appearance after ovariohysterectomy.

True vaginal prolapse is a very rare condition in the bitch, which mainly occurs during or shortly after parturition (Schaefers-Okkens, 2001; Ober et al., 2016) as the concentration of serum progesterone declines and that of serum estrogen increases (Singla et al., 2016). Possible predisposing conditions reported in previous studies include dystocia (Alan et al., 2007), constipation (Ober et al., 2016), forced separation during copulation (Singla et al., 2016), intense straining due to intestinal parasitism (Kladakis et al., 2004), increased intra-abdominal pressure from ascites and full term pregnancy (Markandeya et al., 2004; Jayakumar et al., 2016). Herniation of other abdominal organs, such as urinary bladder, uterine body or part of the colon could be present in the prolapsed vagina (Wikes, 1986). In this case, only the uterine corpus was observed within the prolapsed vagina.

The most interesting and unique fact was that the prolapse occurred as a complication of abortion without signs of dystocia after the expulsion of the foetuses. During the pregnancy the placenta secretes relaxin, which is the only pregnancy-specific hormone in the bitch with peak concentrations 2 to 3 weeks before parturition (Johnston et al., 2001). Relaxin acts on fibrocartilaginous ligaments of the pubic symphysis and other bones of the birth canal, relaxes them, and thus allows dilation and expulsion of the foetus at parturition. The effects of this hormone are potentiated by previous exposure to estrogens (Steinetz et al., 1990). In our opinion, the abortion could be a result of premature decrease in serum progesterone concentration due to an insufficient secretion by the corpora lutea during pregnancy. The decline of progesterone might be a reason for possible elevated levels of estrogens and relaxin which could have caused the pre-partum relaxation of the birth canal and perivaginal tissues and true vaginal prolapse to occur without signs of dystocia.

\section{REFERENCES}

Alan, M., Y. Cetin, S. Sendag \& F. Eski, 2007. True vaginal prolapse in a bitch. Animal Reproduction Science, 20, 411414.

Görlinger, S., S. Galac, H. Kooistra \& A. Okkens, 2005. Hypoluteoidism in a bitch. Theriogenology, 64, 213-219. 
Jayakumar, C., G. Sudha, S. Kantharai \& G. Imam Hussain, 2016. A rare case of complete vaginal prolapse in an advanced pregnant bitch. Indian Journal of Animal Reproduction, 37, 59-60.

Johnston, S., M. Kustritz \& P. Olson, 2001. Canine and Feline Theriogenology. WB Saunders Company, London, United Kingdom.

Kladakis, S., H.Ververidis, T. Anagnastou, L. Papazoglou \& C. Boscos, 2004. Reccurent complete vaginal prolapse with rectal and urethral prolapse in a bitch treated by hysteropexy and colopexy. In: Proceedings of $29^{\text {th }}$ Congress of World Small Animal Veterinary Association, Rhodes, Greece.

Manothaiudom, K. \& S. Johnston, 1991. Clinical approach to vaginal/vestibular masses in the bitch. Veterinary Clinics of North America: Small Animal Practice, 21, 509-521.

Markandeya, N., A. Patil \& A. Bhikane, 2004. Pre-partum vaginal prolapse in a dog. Indian Veterinary Journal, 81, 449.

Ober, C., C. Pestean \& L. Bel, 2016. Vaginal prolapse with urinary bladder incarceration and consecutive irreducible rectal prolapse in a dog. Acta Veterinaria Scandinavica, $\mathbf{5 8}, 54$.

Purswell, B., 2000. Vaginal disorders. In: Textbook of Veterinary Internal Medicine, eds S. J. Ettinger \& E. C. Feldman, WB Saunders Company, London, pp. 1566-1571.

Schaefers-Okkens A., 2001. Vaginal edema and vaginal fold prolapse in the bitch, including surgical management. In: Recent Advances in Small Animal Reproduction, eds P. W. Concannon, G. England \& J.
Verstegen, International Veterinary Information Service (www.ivis.org), Ithaca, New York, USA http://www.ivis.org/advances/Concannon/s chaefers/chapter_frm.asp?FLA=1 March 302018 date last accessed).

Singla V., A. Ahuja, D. Sobti \& N. Gupta, 2016. Management of cervico-vaginal prolapse in a bitch: A case report. Haryana Veterinarian, 55, 241-242.

Steinetz, B., L. Goldsmith, S. Hasan \& G. Lust, 1990. Diurnal variation of serum progesterone, but not relaxin, prolactin, or estradiol-17 $\beta$ in the pregnant bitch. Endocrinology, 127, 1057-1063

Wikes, P., 1986. Diseases of vagina and vulva in the bitch. In: Current Therapy in Theriogenology, ed D. A. Morrow, WB Saunders Company, London, pp. 476-481.

Paper received 18.12.2017; accepted for publication 16.03.2017

\section{Correspondence:}

Anton Antonov, DVM, PhD

Department of Obstetrics, Reproduction and Reproductive Disorders,

Faculty of Veterinary Medicine, Trakia University, 6000 Stara Zagora, Bulgaria, e-mail: anton.antonov@abv.bg 